\title{
MULTIPHASE AUSFORMED AUSTEMPERED DUCTILE IRON
}

\begin{abstract}
Ductile iron was subjected to a total true strain $\left(\varphi_{t}\right)$ of 0.3 either by applying $\varphi_{t}$ in the austenite region or by apportioning it through applying a true strain of 0.2 in the austenite region before quenching to austempering temperature $\left(T_{A}\right)$ of $375^{\circ} \mathrm{C}$, where a true strain of 0.1 is applied (ausforming). Additionally, two types of matrices were produced in the ductile iron, namely ausferritic and ferritic-ausferritic matrices. The ferrite is introduced to the matrix by intercritical annealing after austenitization. Dilatometric measurements as well as microstructure examination showed a fast ausferrite transformation directly after applying $\varphi_{A}$ and that the introduction of ferrite to the matrix resulted in a remarkable acceleration of the ausferrite formation. The transformation kinetics, microstructure evolution, hardness and compression properties are studied.
\end{abstract}

Keywords: Ductile iron, Thermo-mechanical processing, Dual matrix, Austempering, Ausforming, Intercritical annealing

\section{Introduction}

Hot and warm working of cast materials refines the ascast structures, closes up the internal shrinkage cavities and gas porosities, and reduces the segregations of alloying elements. Additionally, they provide deformed and/or recrystallized austenite and thus result in an increased number of sites for the subsequent transformation processes. This method has recently attracted research and industrial interest as a technique for the strength improvement in ductile irons (DI) [1,2]. Forged ductile iron products have been promoted as replacements of some types of steel forgings.

Ausforming of DI is a subdivision of the above-mentioned processing method. The deformation in the ausforming process is introduced into the austempering schedule just after quenching but before any substantial transformation of austenite. It is shown that ausforming could provide mechanical driving force in the form of strain defects in addition to the chemical thermodynamic driving force. This can be used to accelerate the rate of stage I of austempering. The enhanced nucleation rate of ausferrite and $\mathrm{C}$-enriched austenite leads to finer and more homogeneous ausferrite, which in turn, results in a dramatic increase in strength, hardness and wear resistance $[3,4]$.

On the other hand, newly developed DI with dual matrix (DM) is the one of the most recent member the DI family. The matrix structure of DM-DI consists of a soft phase - ferrite and a hard phase - either martensite or ausferrite (acicular ferrite and high carbon austenite). Special interest for such material is due to the improved combination between its strength and ductility and its enhanced machinability compared to the single hard phase matrix $[5,6]$.

In the framework of the current study, hot deformation in the austenitic region after austenitization is combined with introducing of pro-eutectoid ferrite to the matrix to produce thermo-mechanically processed multi-phase ductile iron. Additionally, the effect of ausforming process is investigated. The effect of the processing parameters on the transformation kinetics, microstructure evolution and mechanical behavior is studied.

\section{Experimental procedure}

\subsection{Studied material}

The chemical composition of the investigated ductile iron is given in Table 1. Melting was performed in an induction furnace. The base irons were treated with a $9.5 \mathrm{wt} \% \mathrm{MgFeSi}$ alloy for spheroidisation followed by post-inoculation with $75 \mathrm{wt} \%$ FeSi.

TABLE 1

Composition of the ductile irons (wt.\%)

\begin{tabular}{|c|c|c|c|c|c|c|}
\hline \hline $\mathbf{C}$ & $\mathbf{S i}$ & $\mathbf{M n}$ & $\mathbf{A l}$ & $\mathbf{M g}$ & $\mathbf{S}$ & $\mathbf{P}$ \\
\hline 3.68 & 2.48 & 0.29 & 0.31 & 0.035 & 0.011 & 0.029 \\
\hline
\end{tabular}




\subsection{Thermo-mechanical processing and dilatometry}

For thermo-mechanical processing and dilatometric study, a Baehr Dil 805D thermo-mechanical simulator, shown in Fig. 1, was used. The thermo-mechanical simulation was performed on cylindrical samples of $5 \mathrm{~mm}$ diameter and $10 \mathrm{~mm}$ length. Sheathed type S "Pt/Pt-10\% Rh" thermocouples with a nominal diameter of $0.2 \mathrm{~mm}$ were individually spot welded to the specimens' surface in central position. The sample was mounted horizontally between two SiN stamps. The thermal cycles were performed under vacuum of $0.005 \mathrm{~Pa}$ by inductive heating using a high frequency (HF) generator. Helium was used for cooling. The stamps are not directly heated by induction field and therefore the specimen temperature at the stamps is always lower than that in the middle of the specimen because of heat transfer to the stamps. This results in a temperature gradient towards the stamps. To overcome this problem, two molybdenum disks $(\phi 8 \times 0.36 \mathrm{~mm})$ were spot welded at the parallel ends of the samples to reduce this gradient. Using this method the specimen temperature was homogenized within $+/-7 \mathrm{~K}$. The Mo disks also reduce friction during the compressional test, i.e. serve as a lubricant and so improve the homogeneity of deformation. The dimension variations of the specimens during the thermal-deformation cycle are transmitted via a moving quartz pushrod to a LVDT sensor. A computer and data acquisition system recorded the dilatometric change, temperature and load as a function of time, and cross correlated the relative change in length as a function of temperature.

The specimens are subjected to thermo-mechanical schedules shown in Fig. 2. In these schedules, the specimens were heated up to $960^{\circ} \mathrm{C}$ and subjected to two deformation steps at $960^{\circ} \mathrm{C}$ and $940^{\circ} \mathrm{C}$. The main objective of these deformation steps is to refine the matrix structure through work hardening, recovery and recrystallization effects in austenite. The very slow deformation rate of $0.5 \mathrm{~s}^{-1}$ is adopted to minimize the susceptibility of the specimen to cracking by decreasing the strain hardening effect during deformation [7]. In Schedule 1 (S1): After the last deformation step in the austenite region, the ductile irons are quenched to isothermal holding temperature $T_{A}$ of $375^{\circ} \mathrm{C}$ to obtain ausferritic matrix (Af). In Schedule 2 (S2): The ductile irons are quenched to and isothermally held at temperature $T_{i}$ of $793^{\circ} \mathrm{C}$ within the intercritical region to obtain a predefined quantity of ferrite of about $15 \%$. The methodology of defining $T_{i}$ that introduce a predefined quantity of ferrite to the matrix is described elsewhere [8,9]. Subsequently, the ductile irons are quenched to $T_{A}$ of $375^{\circ} \mathrm{C}$ to obtain ausferrite + ferrite $(\mathrm{Af}+\mathrm{F})$ matrix. In both schedules, two variants of deformations, namely with ausforming and without ausforming are applied as shown in the table attached with the Fig. 2. For the seek of comparison, the total applied true strain in both variants is $\varphi_{t}=0.3$. The austempering time $t_{A}$ corresponds to the time for the end of stage I of transformation, which is processing condition dependent as will be shown.

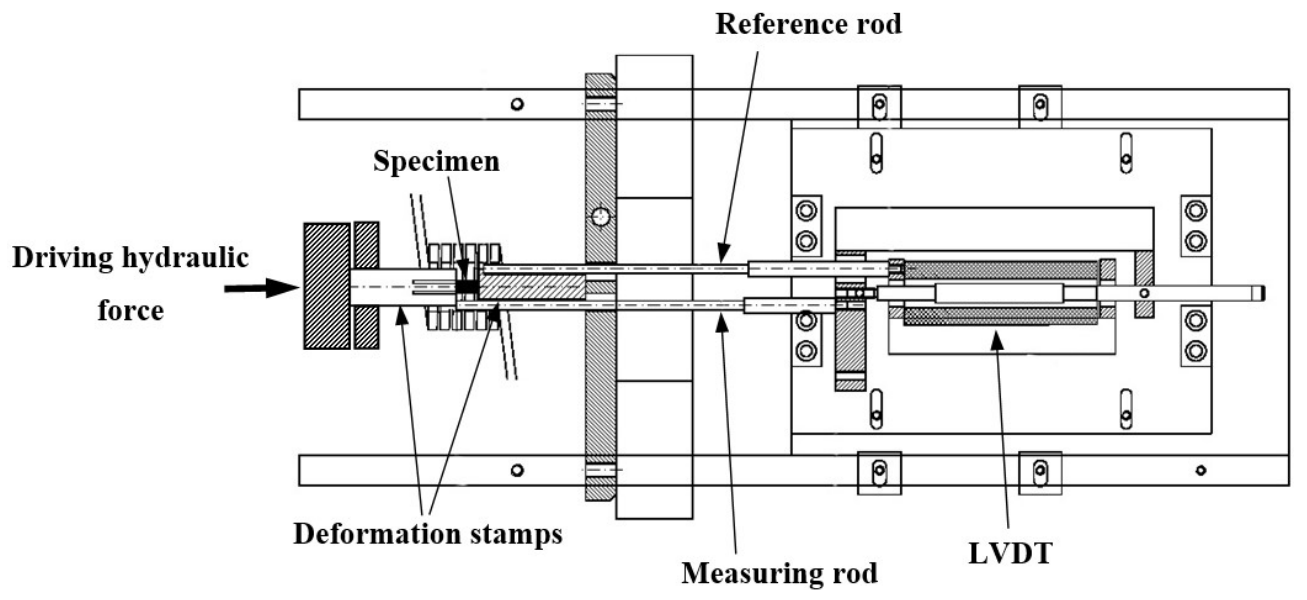

Fig. 1. Schematic drawing of the deformation dilatometer Dil 805D

\section{Results and discussions}

\subsection{Transformation kinetics}

The dilatation-time curves obtained during austempering at $375^{\circ} \mathrm{C}$ of the ductile iron are shown in Fig. 3. The samples expansion is due to the transformation of austenite into ausferrite. Both of deforming the austenite prior to the transformation stage I and introduction of ferrite pronouncedly accelerated the transformation kinetics. It is observable also that ausferrite transformation takes place directly after applying $\varphi_{A}$. For Schedule 1 (S1): The transformation requires about $1800 \mathrm{~s}$ to reach its saturation when the DI is not ausformed. Ausforming the ductile iron accelerated the transformation so that the transformation saturation is achieved after about $600 \mathrm{~s}$. The acceleration of ausferrite reaction due to ausforming is correlated to the much larger number of ferrite particles nucleating on defects (e.g. dislocations, twins, etc.) caused by deformation. The higher nucleation rate of the ferrite-platelets increases the kinetics of ausferrite transformation as the carbon atoms diffusing away from the ferrite will have to migrate for shorter distances within the austenite to establish the high carbon austenite in metastable equilibrium with the ferrite [10]. Thus, the times needed for processing following the ausforming step are considerably reduced compared to processing non-ausformed DI. 

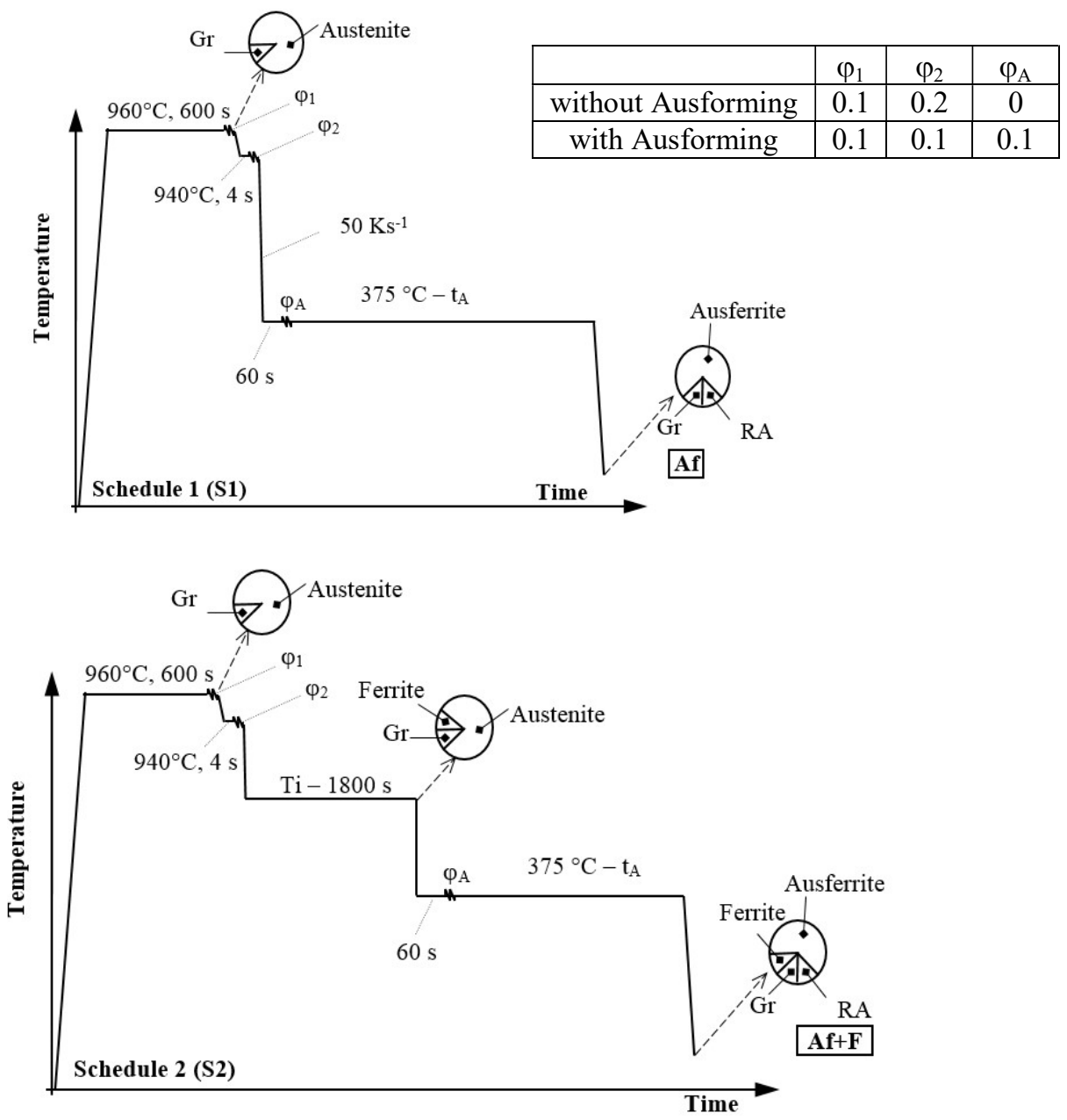

Fig. 2. Thermo-mechanical schedules applied to the four ductile irons, Gr: graphite, RA: retained austenite and $T_{A}$ : austempering temperature

In schedule 2 the introduction of ferrite to the microstructure, before austempering, has also a pronounced effect on accelerating the kinetics of ausferrite formation and reduction of the incubation period of transformation. This can be attributed to:

1. The increased number of sites for the nucleation of acicular ferrite at the ferrite austenite interface.

2. The reduced carbon content of the intercritical austenite during the isothermal holding at the intercritical annealing temperature. That is during cooling to and isothermal holding at $T_{i}, \mathrm{C}$ atoms diffuse from the austenite matrix to the nodule; that is because the saturation level of austenite with $\mathrm{C}$ decreases with decreasing temperature. The decrease in the thermal expansivity of the austenite lattice by lowering the temperature is the reason for the rejection of $\mathrm{C}$ from the austenite during cooling $[9,11]$.

The introduction of $15 \%$ of ferrite to the matrix seems to have stronger effect on accelerating the ausferrite formation than the effect of applying $\varphi_{A}=0.1$ as can be inferred from Fig. 3 . The introduction of ferrite reduced the time required for transformation saturation to about $500 \mathrm{~s}$ which is about $100 \mathrm{~s}$ less than the
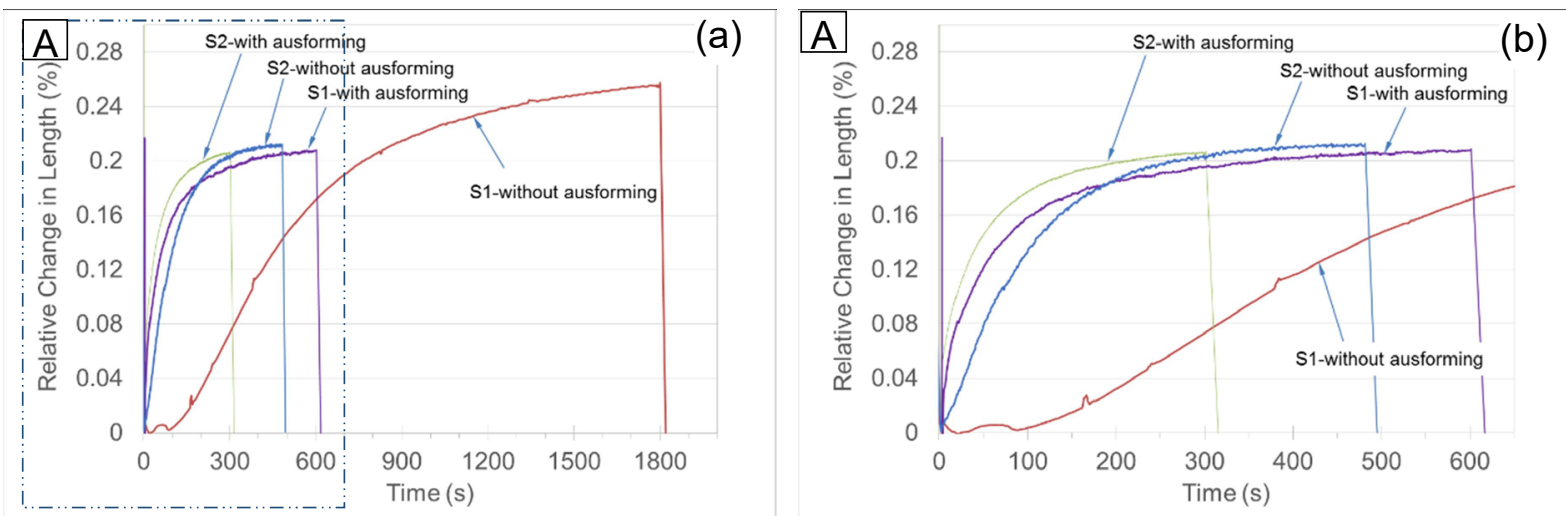

Fig. 3. Kinetics of ausferrite formation for the prescribed processing techniques. In (b) details of section A 
that of the ausformed DI. However the transformation of the ausformed DI starts faster but proceeds at slower rate compared to the DI with introduced ferrite.

The ausferrite formation time is reduced to about $300 \mathrm{~s}$ in the case of introducing ferrite to the matrix by intercritical annealing and ausforming the ductile iron

\subsection{Microstructure evolution}

The acceleration of kinetics of ausferrite formation due to the ausforming is confirmed from the micrographs of the microstructure development shown in Fig. 4. Considering schedule 1 without ausforming, it is remarkable that the ausferrite largely starts to form away from the nodules such that the last formed ausferrite occurs around the nodules. During austenitization the carbon defuses from the nodules to the matrix such that the neighbourhood of the nodules possess higher carbon content and hence higher resistance to transform to ausferrite. However, when ausforming the DI, the first formed ausferrite occurs around the nodules. The ausforming process results in increasing the nucleation sites of ausferrite to a great extent. The graphite nodules, which act as stress concentrators would promote localized higher concentration of dislocations around the nodules and hence higher stimulation of ausferrite nucleation. It seems that this stimulation effect is stronger than the retardation effect of
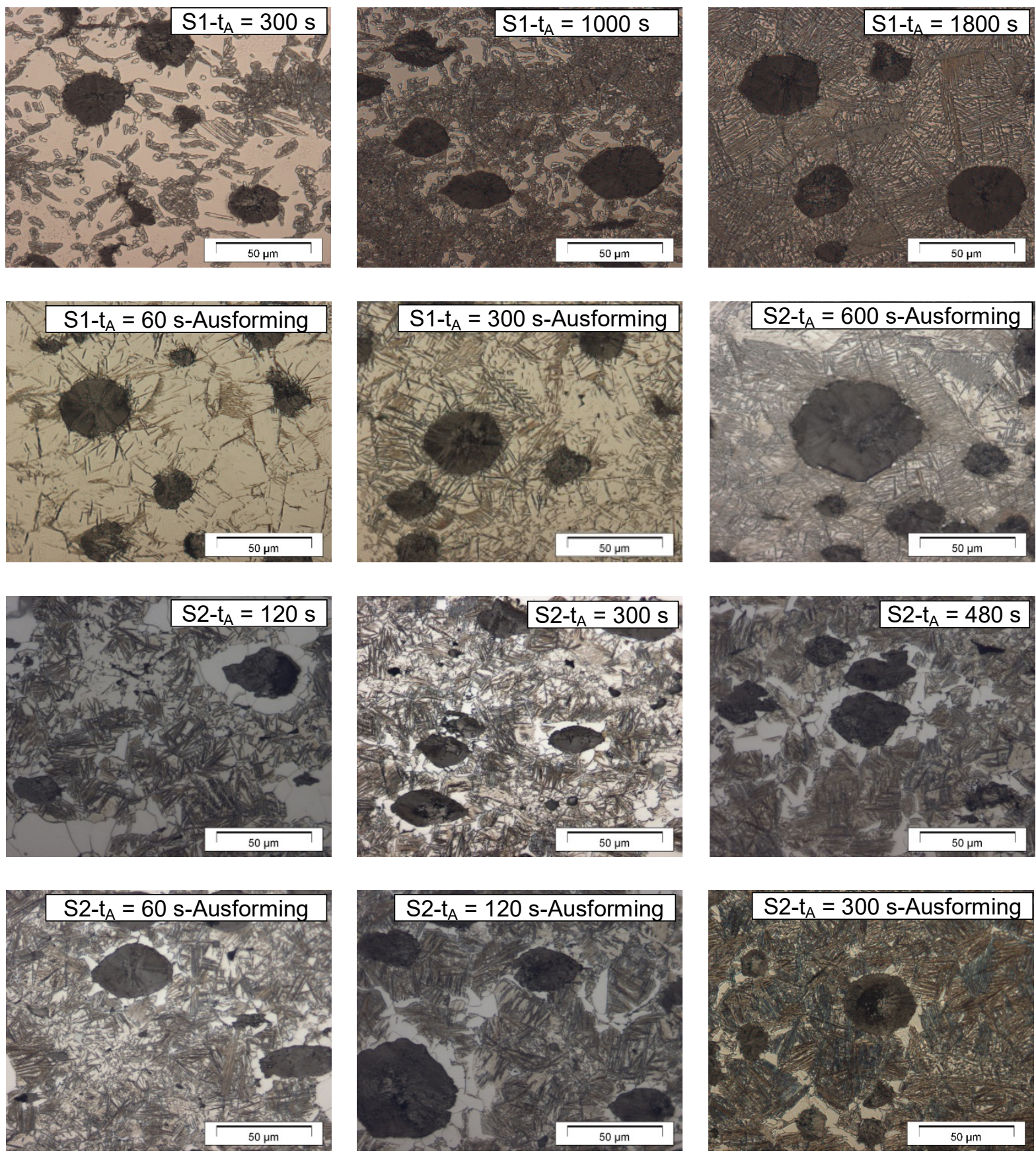

Fig. 4. Micrographs showing acceleration of kinetics of ausferrite formation due to the ausforming process and introduction of ferrite to the matrix of DI. $t_{A}$ : holding time after quenching to $T_{A}$ 

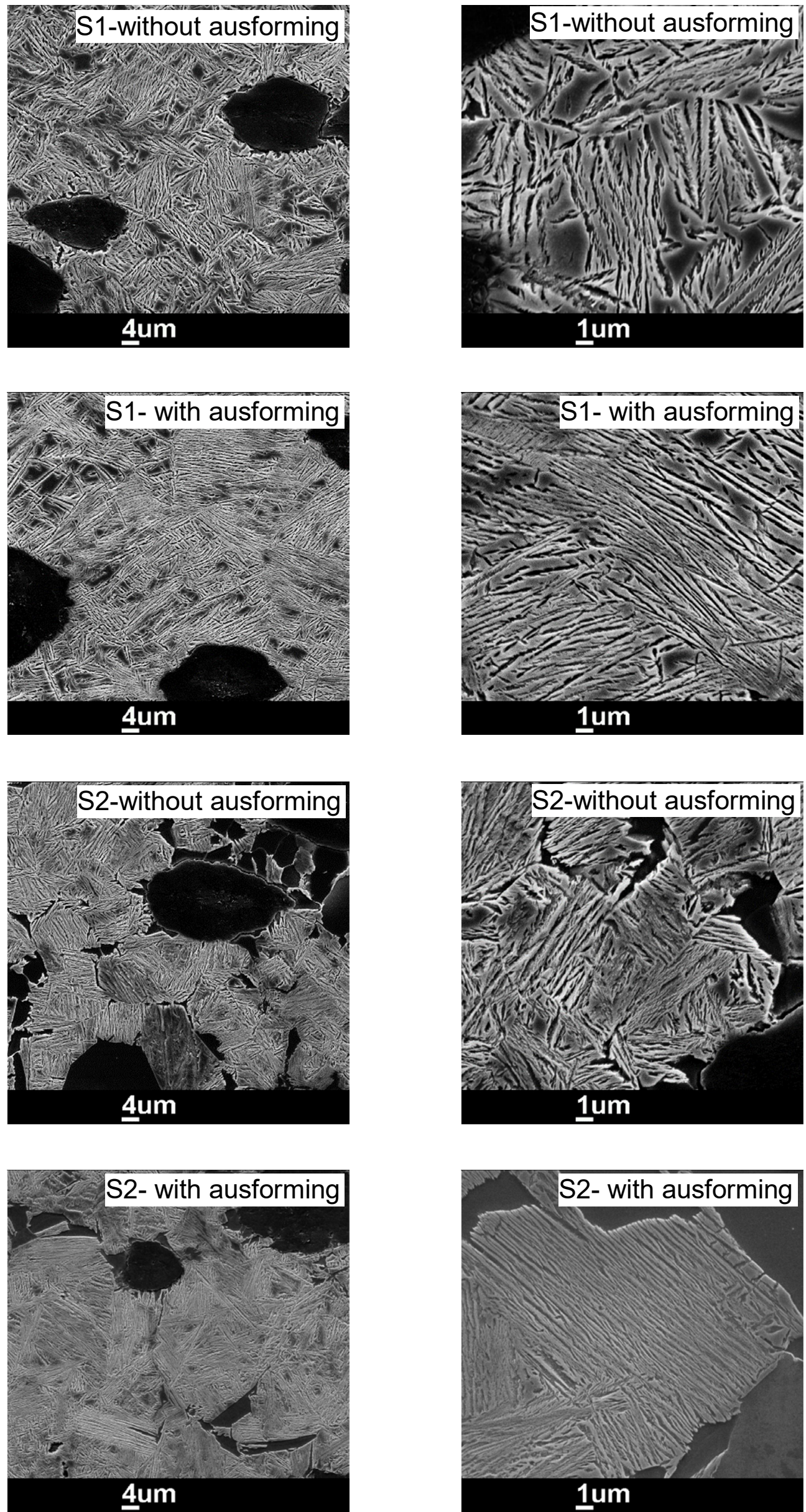

Fig. 5. SEM structures observed after quenching of the prescribed processing conditions 
ausferrite formation due to the carbon localisation around the nodules thus the ausferrite start to form around the nodules in case of the ausformed DI subjected to schedule 1.

In case of schedule 2, the ausferrite starts to form around the ferrite and the last ausferrite is formed remotely from the nodules and ferrite grains. This is applicable for both the ausformed and non-ausformed cases.

The samples subjected to schedule II revealed blocky austenite of smaller size and less quantity than that of schedule I. Other form of retained austenite that could not be resolved using the LOM is the fine interlath films inside the ausferrite aggregates. In order to distinguish these individual austenite plates within the thin aggregates of the ausferrite, SEM investigations had been conducted.

Fig. 5 shows that the ferrite aggregates build up from many ferrite plates in the same crystallographic orientation. Myszka et al. reported that isothermal transformation of ausferrite refines the ferrite plates which tend to form a typical feathery pattern indicating the direction of the plate growth [12]. It is obvious in Fig. 5 that the retained austenite is present in a form of homogenously distributed films along ferrite plate boundaries as well as in a form of small isolated austenite colonies. The polygonalferrite phase is easily distinguishable within the structure. The comparison of the ausformed ausferrite morphology with the non-ausformed one for both of the applied schedules indicates the impact of ausforming on enhancing the microstructural uniformity and refining the ausferrite platelets. The observed refinement is mainly a consequent of the increased nucleation sites of the ausferrite-platelets

\subsection{Mechanical behaviour}

Table 2 shows the compression and hardness properties of the investigated ductile iron. The remarkable increase in hardness, strength and ductility of the ausformed ductile irons is not only attributed to the structure refinement associated with the ausforming process but also to the increased dislocation density in the bainitic ferrite due to the warm working. Increasing the dislocation density results in elevated yield and ultimate strengths. It is reported that the increased dislocation density in the bainitic ferrite following warm working of austenite plays a role in increasing the yield strength of steel [13].

TABLE 2

Mechanical characteristics of the DI

\begin{tabular}{|c|c|c|c|c|c|}
\hline \hline \multicolumn{2}{|c|}{ Condition } & HV20 & CS & YS & FS \\
\hline \multirow{2}{*}{ S1 } & Without Ausforming & 301 & 1447 & 689 & 0.46 \\
\cline { 2 - 6 } & With Ausforming & 356 & 1671 & 960 & 0.58 \\
\hline \multirow{2}{*}{ S2 } & Without Ausforming & 274 & 984 & 521 & 0.47 \\
\cline { 2 - 6 } & With Ausforming & 282 & 1008 & 726 & 0.45 \\
\hline
\end{tabular}

CS: Compression strength, YS: Yield strength in compression and FS: Fracture strain.
On the other hand, the impact of ausforming on the mechanical behaviour is stronger when applying schedule 1, i.e. the ferrite free matrix compared to its impact when applying schedule 2 (with introduced ferrite to the matrix).

\section{Summary}

This work highlights transformation kinetics, microstructure evolution and mechanical behavior of thermo-mechanically processed ductile irons. Two types of matrices were produced in the ductile iron, namely ausferritic and ferritic-ausferritic matrices. Furthermore, the ductile iron is deformed applying a total true strain of 0.3 in the austenite region one time and 0.2 in the austenite region and 0.1 during austempering (ausforming) other time. Both of ausforming and ferrite-introduction to the matrix accelerate the ausferrite transformation kinetics. The ausforming process has its impact on enhancing the microstructural uniformity and refining the ausferrite platelets. Such microstructural variations result in remarkable increase in hardness, strength and ductility of the ausformed ductile iron.

\section{REFERENCES}

[1] M. Soliman, H. Palkowski, A. Nofal, Key Eng. Mater. 457, 199204 (2011).

[2] K. Qi, F. Yu, F. Bai, Z. Yan, Z. Wang, T. Li, Mater. and Design 30, 4511-4515 (2009).

[3] A. Nofal, J. Metall. Eng. 2, 1-18 (2013).

[4] A. Nofal, The current status of the metallurgy and processing of austempered ductile iron (ADI), 10th International Symposium on the Science and Processing of Cast Iron (SPCI 10), November 2014 (Mar del Plata Argentina), INTEMA-Argentina

[5] T. Kobayashi, S. Yamada, Metall. Mater. Trans. A 27, 1961-1971 (Jul. 1996).

[6] N. Wade, C. Lu, Y. Ueda, T. Maeda, Trans. Japn. Foundarymen's Soc. 4, 22-26 (Apr. 1985).

[7] G.E. Dieter, H.A. Kuhn and S.L. Semiatin, Handbook of Workability and Process Design, 2003 USA.

[8] M. Soliman, H. Palkowski, A. Nofal, Key Eng. Mater. 457, 199204 (2011).

[9] M. Soliman, A. Nofal, H. Palkowski, Alloy and process design of thermo-mechanically processed multiphase ductile iron, Materials and Design 87, 450-465 (2015).

[10] H. Nasr El-Din, A.A. Nofal, K.M. Ibrahim, A.A. Ramadan, International Journal of Cast Metals Research 19, 137-150 (2006).

[11] N. Darwish, R. Elliot, Mater. Sci. Technol. 9, 882-889 (1993).

[12] D. Myszka, E. Skołek, A. Wieczorek, Arch. Metall. Mater. 59, 1217-1221 (2014).

[13] R.H. Edwards, N.F. Kennon, Metall. Trans. 9A, 1801-1809(1978). 